\title{
Low dark current metal-semiconductor-metal photodiodes based on semi-insulating GaN
}

Serkan Butun, Mutlu Gökkavas, HongBo Yu, and Ekmel Ozbay

Citation: Appl. Phys. Lett. 89, 073503 (2006); doi: 10.1063/1.2234741

View online: http://dx.doi.org/10.1063/1.2234741

View Table of Contents: http://aip.scitation.org/toc/apl/89/7

Published by the American Institute of Physics

\section{Articles you may be interested in}

Assessment of GaN metal-semiconductor-metal photodiodes for high-energy ultraviolet photodetection Applied Physics Letters 80, 3198 (2002); 10.1063/1.1475362

Gain mechanism in GaN Schottky ultraviolet detectors

Applied Physics Letters 79, 1417 (2001); 10.1063/1.1394717

Visible-blind GaN Schottky barrier detectors grown on $\mathrm{Si}(111)$

Applied Physics Letters 72, 551 (1998); 10.1063/1.120755

Comprehensive characterization of metal-semiconductor-metal ultraviolet photodetectors fabricated on singlecrystal GaN

Journal of Applied Physics 83, 6148 (1998); 10.1063/1.367484

Growth of high crystalline quality semi-insulating GaN layers for high electron mobility transistor applications Journal of Applied Physics 100, 033501 (2006); 10.1063/1.2221520

Ultrafast metal-semiconductor-metal photodetectors on low-temperature-grown GaN

Applied Physics Letters 86, 211110 (2005); 10.1063/1.1938004

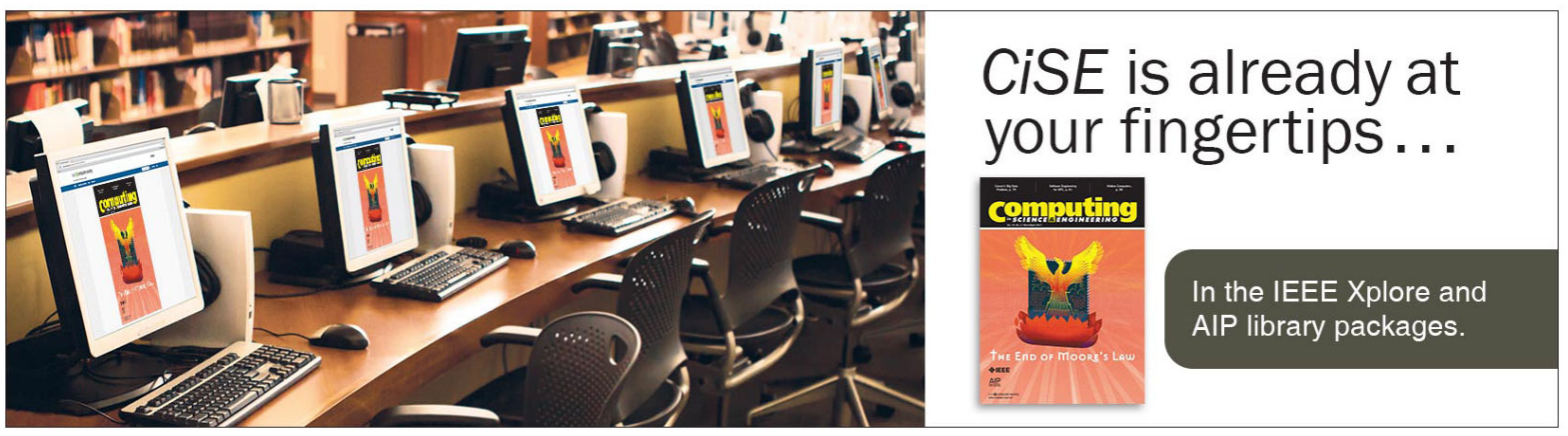




\title{
Low dark current metal-semiconductor-metal photodiodes based on semi-insulating GaN
}

\author{
Serkan Butun ${ }^{\text {a) }}$ \\ Nanotechnology Research Center, Bilkent University, Bilkent, Ankara 06800, Turkey \\ and Department of Physics, Bilkent University, Bilkent, Ankara 06800, Turkey \\ Mutlu Gökkavas and HongBo Yu \\ Nanotechnology Research Center, Bilkent University, Bilkent, Ankara 06800, Turkey \\ Ekmel Ozbay \\ Nanotechnology Research Center, Bilkent University, Bilkent, Ankara 06800, Turkey; \\ Department of Physics, Bilkent University, Bilkent, Ankara 06800, Turkey; and Department of Electrical \\ and Electronics Engineering, Bilkent University, Bilkent, Ankara 06800, Turkey
}

(Received 5 April 2006; accepted 2 June 2006; published online 15 August 2006)

\begin{abstract}
Metal-semiconductor-metal photodetectors on semi-insulating GaN templates were demonstrated and compared with photodetectors fabricated on regular GaN templates. Samples were grown on a metal organic chemical vapor deposition system. Devices on semi-insulating template exhibited a dark current density of $1.96 \times 10^{-10} \mathrm{~A} / \mathrm{cm}^{2}$ at $50 \mathrm{~V}$ bias, which is four orders of magnitude lower compared with devices on regular template. Device responsivities were 101.80 and $88.63 \mathrm{~A} / \mathrm{W}$ at $50 \mathrm{~V}$ bias for $360 \mathrm{~nm}$ ultraviolet illumination for semi-insulating and regular templates, respectively. Incident power as low as $3 \mathrm{pW}$ was detectable using the devices that were fabricated on the semi-insulating template. (C) 2006 American Institute of Physics. [DOI: 10.1063/1.2234741]
\end{abstract}

Solid state photodetectors based on $\mathrm{Al}_{x} \mathrm{Ga}_{1-x} \mathrm{~N}$ based $(0 \leqslant x \leqslant 1)$ heterostructures are promising candidates for photodetection in the ultraviolet (UV) spectrum from the near UV to deep UV. A variety of UV photodetectors, such as Schottky barrier, ${ }^{1,2} p-i-n,,^{3-5}$ and metalsemiconductor-metal $^{6-8}$ (MSM) photodetectors, based on this material system have been reported in the literature. Although structures with high $\mathrm{Al}$ content exhibited low dark current values, there have only been a few reports regarding relatively low dark current devices fabricated on GaN. The best result was around $10 \mathrm{pA}$ at $100 \mathrm{~V}$ bias. ${ }^{9}$ In this letter, we report the fabrication and characterization of MSM photodetectors that are based on semi-insulating (SI) GaN. Identical devices fabricated on regular unintentionally doped (UD) GaN epilayers were used to make a comparison and evaluate the improvement by using the SI-GaN template.

The samples in this study were all grown on $c$-face (0001) sapphire substrates by low-pressure metal organic chemical vapor deposition (MOCVD). Hydrogen was used as the carrier gas, and trimethylgallium (TMGa), trimethylaluminum (TMAl), and ammonia $\left(\mathrm{NH}_{3}\right)$ were used as the $\mathrm{Ga}$, $\mathrm{Al}$, and $\mathrm{N}$ sources, respectively. SI-GaN layer was grown on high temperature AlN buffer. Prior to the epitaxial growth, sapphire substrates were annealed at $1100{ }^{\circ} \mathrm{C}$ for $10 \mathrm{~min}$ to remove surface contamination, and subsequently a $15 \mathrm{~nm}$ thick AlN nucleation layer was deposited at $840^{\circ} \mathrm{C}$. Thereafter, the reactor temperature was ramped to $1150^{\circ} \mathrm{C}$ and an AlN buffer layer was grown, followed by a 2 min growth interruption in order to reach optimum growth conditions for $\mathrm{GaN}$. The growth conditions of $\mathrm{GaN}$ were as follows: reactor pressure of 200 mbars, growth temperature of $1070{ }^{\circ} \mathrm{C}, \mathrm{H}_{2}$ carrier gas, and growth rate about $2 \mu \mathrm{m} / \mathrm{h}$. A typical UD-GaN control sample was grown on sapphire substrate

\footnotetext{
${ }^{a)}$ Electronic mail: butun@ fen.bilkent.edu.tr
}

using the two-step method with a low temperature GaN nucleation layer deposited at $500{ }^{\circ} \mathrm{C}$. For a fair comparison, the thickness and growth parameters of the high temperature $\mathrm{GaN}$ (HT-GaN) layers in the two samples were kept constant.

We used a four-step microwave compatible process in a class-100 clean room environment to fabricate the MSM photodiodes. We started with the deposition of $100 \AA / 1000 \AA$ thick interdigitated Ni/Au fingers on the surface of the UD-GaN and SI-GaN layers of the two samples. Finger width and spacing of fabricated devices varied between 3 and $20 \mu \mathrm{m}$, while active detector areas were 100 $\times 100$ and $200 \times 200 \mu \mathrm{m}^{2}$. Following finger deposition, the device mesas were defined by reactive ion etching. Next, a $120 \mathrm{~nm}$ thick $\mathrm{Si}_{3} \mathrm{~N}_{4}$ layer was deposited by a plasma enhanced chemical vapor deposition (PECVD) system for the surface passivation of the samples. The $\mathrm{Si}_{3} \mathrm{~N}_{4}$ layer was also used as an antireflection layer as well as for protecting the metal fingers. Finally, fabrication was finalized by the deposition of $10 \mathrm{~nm} / 400 \mathrm{~nm}$ thick $\mathrm{Ti} / \mathrm{Au}$ interconnect pads. In addition, the transmission line method (TLM) patterns were prepared by the deposition of $100 \AA / 400 \AA / 100 \AA / 400 \AA$ $\mathrm{Ti} / \mathrm{Al} / \mathrm{Ni} / \mathrm{Au}$ contact pads on separate samples. The TLM patterns used for sheet resistivity calculations consisted of $200 \times 100 \mu \mathrm{m}^{2}$ pads with separations in the 5-50 $\mu \mathrm{m}$ range. The contacts were annealed at $750{ }^{\circ} \mathrm{C}$ for $1 \mathrm{~min}$ in a rapid thermal processor oven.

We calculated the sheet resistivities of the two samples using standard TLM measurements. Current-voltage (I-V) characterization of the contact pads was carried out with an HP4142B semiconductor parameter analyzer. The sheet resistances of the SI-GaN and UD-GaN samples were calculated as $3.16 \times 10^{11}$ and $5.8 \times 10^{7} \Omega /$ sq, respectively.

Current-voltage characterization of the fabricated MSM photodiodes was carried out using a Keithley 6517A high resistance electrometer with low noise triaxialcables. The de- 


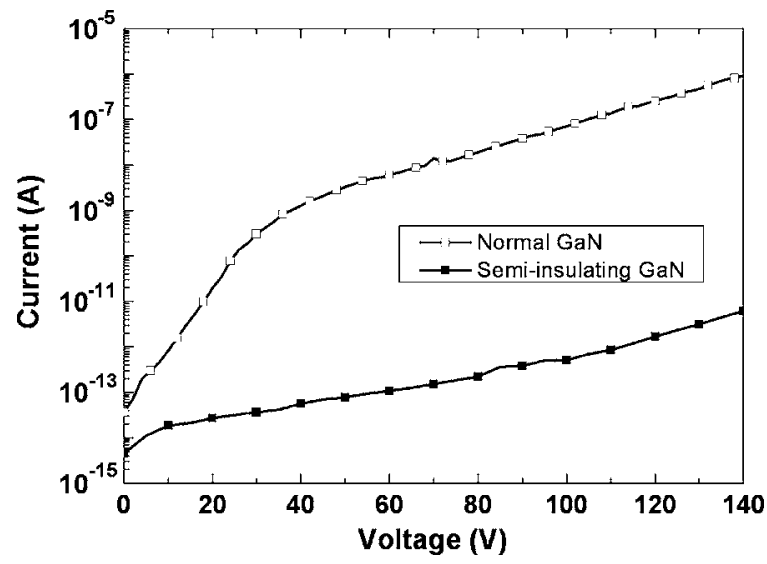

FIG. 1. Current-voltage characteristics of $200 \times 200 \mu \mathrm{m}^{2}$ MSM photodiodes with $10 \mu \mathrm{m} / 10 \mu \mathrm{m}$ finger width/spacing on two different chips.

vices fabricated on the SI-GaN sample exhibited extremely low dark currents, while those fabricated on the UD-GaN sample exhibited higher dark currents, which is typical for such devices. No breakdown was observed for bias voltages as high as $200 \mathrm{~V}$ for $200 \times 200 \mu \mathrm{m}^{2}$ active area detectors fabricated on the SI-GaN and UD-GaN samples. Figure 1 compares the dark $I-V$ curves of $10 \mu \mathrm{m}$ finger width/spacing devices from the two chips. The dark current measured from devices fabricated on the SI-GaN chip remains below $1 \mathrm{pA}$ and up to $100 \mathrm{~V}$ bias voltage. The dark current density (at $50 \mathrm{~V}$ bias) of a device fabricated on the SI-GaN chip is calculated as $1.96 \times 10^{-10} \mathrm{~A} / \mathrm{cm}^{2}$. In comparison, the $50 \mathrm{~V}$ dark current density calculated for a similar device fabricated on the UD-GaN chip is $8.1 \times 10^{-6} \mathrm{~A} / \mathrm{cm}^{2}$, which corresponds to four orders of magnitude improvement.

Spectral responsivity measurements of both samples were performed in the range of $250-450 \mathrm{~nm}$ using a Xe arc lamp, a monochromator, and a calibrated $\mathrm{Si}$ photodetector which is calibrated through the range of $190-1100 \mathrm{~nm}$. Photocurrent was measured in two different ways: The dc (unmodulated) photocurrent was measured using a high resistance electrometer, whereas the ac (modulated) photocurrent was recorded by a lock-in amplifier using an optical chopper to modulate the monochromator output. Figure 2 illustrates unmodulated responsivity curves as a function of applied bias voltage for $200 \times 200 \mu \mathrm{m}^{2}$ devices with $3 \mu \mathrm{m} / 3 \mu \mathrm{m}$ finger width/spacing on the two different chips.

Devices on both chips exhibited a sharp cutoff at $365 \mathrm{~nm}$, while the peak of the photoresponse was observed at $360 \mathrm{~nm}$. Device responsivity increased with applied voltage and reached $101.80 \mathrm{~A} / \mathrm{W}$ for SI GaN and $88.63 \mathrm{~A} / \mathrm{W}$ for UD GaN at $50 \mathrm{~V}$ bias and $365 \mathrm{~nm} \mathrm{UV}$ illumination. These very high responsivity values indicate that devices have a gain of about 700 that can be attributed to the photoconductive gain mechanism in MSM detectors. Using thermally limited detectivity $\left(D^{*}\right)$ formula, ${ }^{10} D^{*}=R_{\lambda} \sqrt{R_{0} A / 4 k T}$, where $R_{\lambda}$ is device responsivity at $0 \mathrm{~V}$ bias, $R_{0}$ is differential resistance, and $A$ is the device area, we find detectivity values of $1.3 \times 10^{14}$ and $1.2 \times 10^{13} \mathrm{~cm} \mathrm{~Hz}^{1 / 2} / \mathrm{W}$ at $360 \mathrm{~nm}$ at $0 \mathrm{~V}$ bias for SI-GaN and UD-GaN chips, respectively. Detectivity of the SI-GaN sample reached 3.12 $\times 10^{17} \mathrm{~cm} \mathrm{~Hz}^{1 / 2} / \mathrm{W}$ at $50 \mathrm{~V}$ bias. These detectivity values are the best results reported in the literature for a GaN based MSM photodiode. These high detectivity values are even comparable with those of photomultiplier tubes and AlGaN

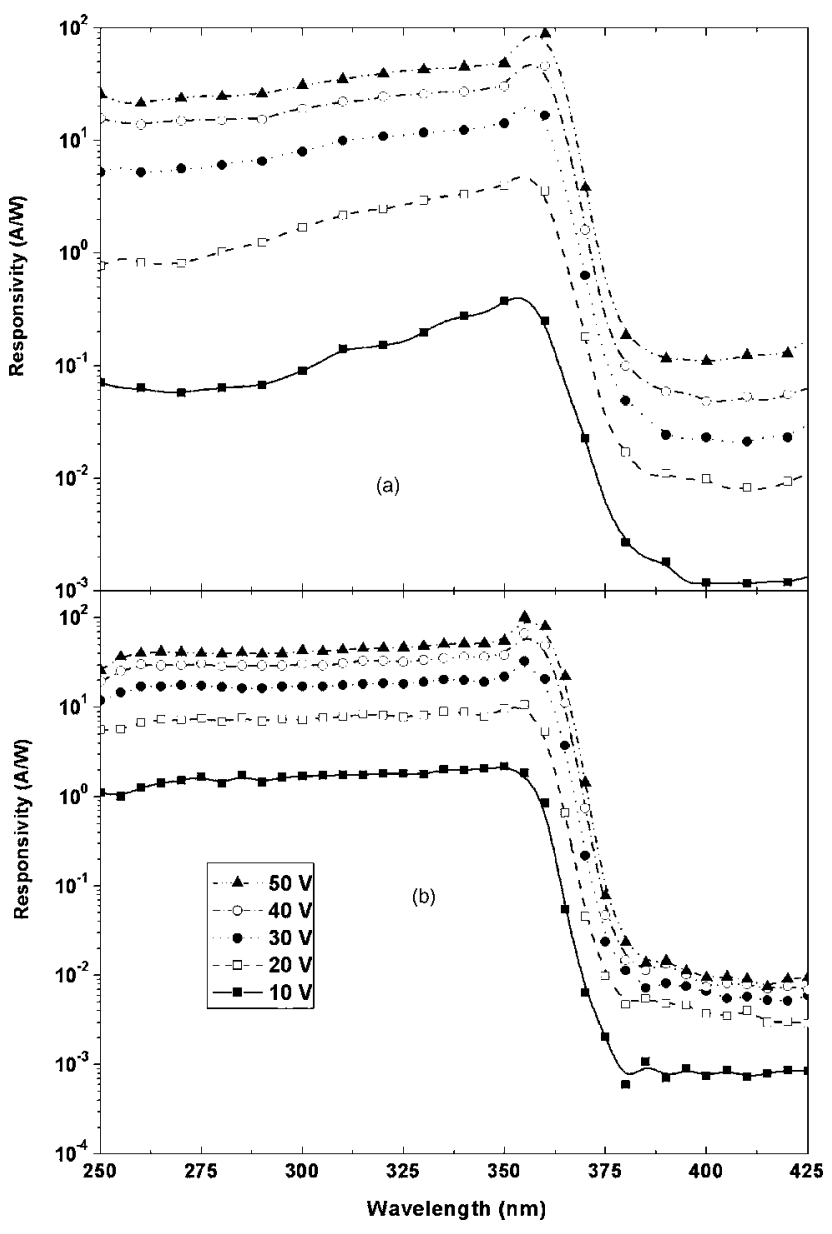

FIG. 2. Measured spectral responsivity curves of $200 \times 200 \mu \mathrm{m}^{2}$ devices with $3 \mu \mathrm{m} / 3 \mu \mathrm{m}$ finger width/spacing on the (a) UD-GaN chip and (b) SI-GaN chip as a function of applied bias voltage.

based photodetectors. ${ }^{11,12}$ We also performed a modulated photoresponse measurement in order to investigate the dependence of the gain on modulation frequency. Figure 3 shows the photoresponse of a device on the SI-GaN sample. Although device responsivity decreases with the chopper frequency as expected, ${ }^{13}$ a significant gain is observed even at the setup high frequency limit of $400 \mathrm{~Hz}$.

Finally, a low optical power responsivity measurement was performed in order to determine the minimum detectable

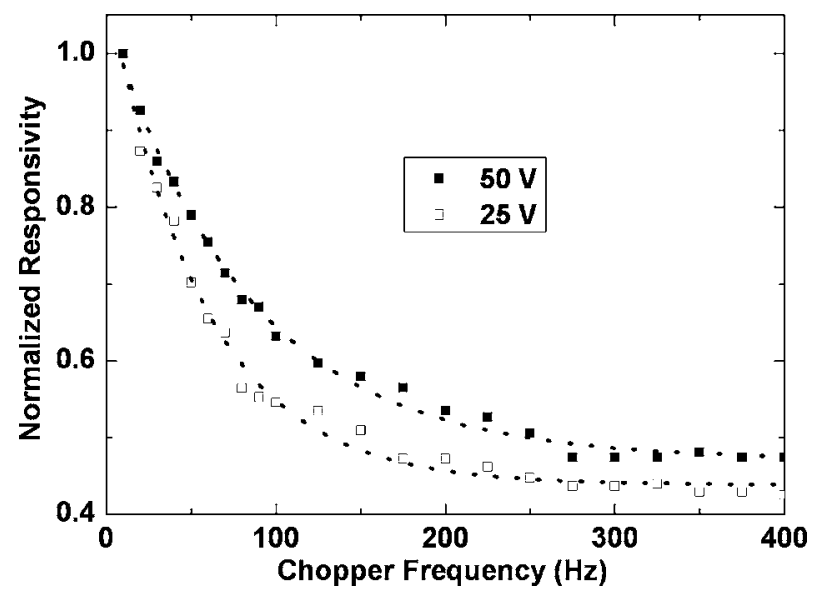

FIG. 3. Normalized modulated photoresponse of a $200 \times 200 \mu \mathrm{m}^{2}$ device with $3 \mu \mathrm{m} / 3 \mu \mathrm{m}$ finger width/spacing on the SI-GaN chip as a function of chopper frequency. 


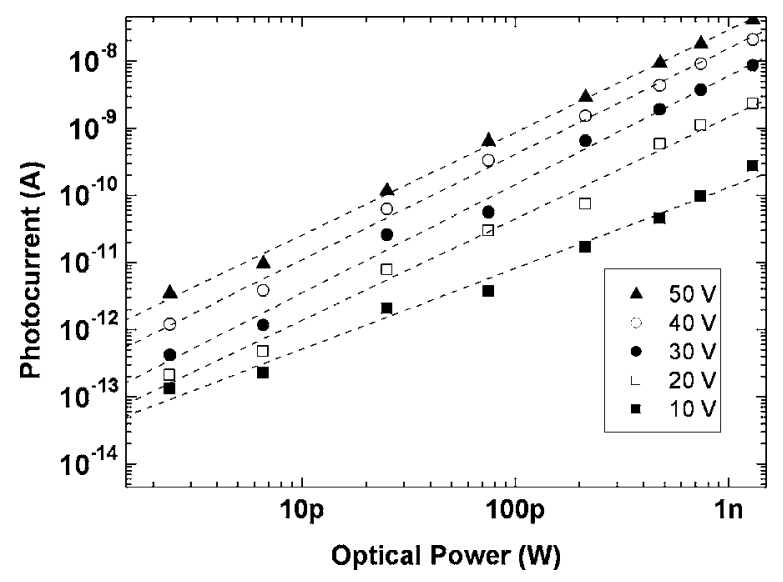

FIG. 4. Measured photocurrent of a $200 \times 200 \mu \mathrm{m}^{2}$ device with $3 \mu \mathrm{m} / 3 \mu \mathrm{m}$ finger width/spacing on the SI-GaN chip as a function of optical power and bias voltage. The dashed lines represent linear fits to the plotted data.

optical power. A series of neutral density filters were used to vary the incident optical power in the range of a few picowatts to $1 \mathrm{nW}$. As expected, very low level signals are detectable because of the large gain and low dark current values. As shown in Fig. 4, the measured dc photocurrent is well above the dark current at the corresponding bias voltage even for incident optical powers as low as $3 \mathrm{pW}$.

In conclusion, we have fabricated and tested MSM photodiodes on SI-GaN templates. We also compared these devices with identical ones fabricated on a regular UD-GaN control sample. Devices on the SI-GaN chip exhibited a dark current density of $1.96 \times 10^{-10} \mathrm{~A} / \mathrm{cm}^{2}$ at $50 \mathrm{~V}$ bias voltage, which is four orders of magnitude lower compared with that of the devices on the UD-GaN chip. No sign of device breakdown was observed at bias voltages as high as $200 \mathrm{~V}$ for both samples. For $360 \mathrm{~nm}$ UV illumination and at $50 \mathrm{~V}$ bias, responsivity values as high as 101.8 and $88.63 \mathrm{~A} / \mathrm{W}$ were obtained from the SI- and UD-GaN samples, respectively.
Photoresponse of both samples was comparable with no significant difference. All of the devices exhibited relatively flat response in the $250-360 \mathrm{~nm}$ range with a sharp cutoff at $365 \mathrm{~nm}$. Because of high internal gain and low dark current, MSM photodetectors fabricated on SI-GaN templates can detect low level optical signals on the order of a few picowatts.

This work was supported by EU NOE-PHOREMOST, EU NOE-METAMORPHOSE, and TUBITAK under Project Nos. 104E090, 105E066, and 105A005. One of the authors (E.O.) acknowledges partial support from the Turkish Academy of Sciences.

${ }^{1}$ A. Osinsky, S. Gangopadhyay, B. W. Lim, M. Z. Anwar, M. A. Khan, D. V. Kuksenkov, and H. Temkin, Appl. Phys. Lett. 72, 742 (1998).

${ }^{2}$ T. Tut, N. Biyikli, I. Kimukin, T. Kartaloglu, O. Aytur, M. S. Unlu, and E. Ozbay, Solid-State Electron. 49, 117 (2005).

${ }^{3}$ U. Chowdhury, M. M. Wong, C. J. Collins, B. Yang, J. C. Denyszyn, J. C. Campbell, and D. Dupuis, J. Cryst. Growth 248, 552 (2003).

${ }^{4}$ C. J. Collins, U. Chowdhury, M. M. Wong, B. Yang, A. L. Beck, R. D. Dupuis, and J. C. Campbell, Appl. Phys. Lett. 80, 3754 (2002).

${ }^{5}$ M. M. Wong, U. Chowdhury, C. J. Collins, B. Yang, J. C. Denyszyn, K. S. Kim, J. C. Campbell, and R. D. Dupuis, Phys. Status Solidi A 188, 333 (2001).

${ }^{6}$ T. Li, D. J. H. Lambert, A. L. Beck, C. J. Collins, B. Yang, J. M. M. Wong, U. Chowdhury, R. D. Dupuis, and J. C. Campbell, Electron. Lett. 36, 1581 (2000).

${ }^{7}$ N. Biyikli, I. Kimukin, T. Kartaloglu, O. Aytur, and E. Ozbay, Phys. Status Solidi C 7, 2314 (2003).

${ }^{8}$ J. Y. Duboz, J. L. Reverchon, D. Adam, B. Damilano, N. Grandjean, F. Semond, and J. Massies, J. Appl. Phys. 92, 5602 (2002).

${ }^{9}$ E. Monroy, T. Palacios, O. Hainaut, F. Omnes, F. Calle, and J. F. Hochedez, Appl. Phys. Lett. 80, 3198 (2002).

${ }^{10}$ S. Donati, Photodetectors: Devices, Circuits, and Applications (PrenticeHall, Upper Saddle River, NJ, 2000), p. 43.

${ }^{11}$ J. D. Brown, Z. Yu, J. Matthews, S. Harney, J. Boney, J. F. Schetzina, J. D. Jenson, K. W. Dang, C. Terrill, T. Nohava, W. Yang, and S. Krishnankutty, MRS Internet J. Nitride Semicond. Res. 4, 9 (1999).

${ }^{12}$ N. Biyikli, I. Kimukin, O. Aytur, and E. Ozbay, IEEE Photonics Technol. Lett. 16, 1718 (2004).

${ }^{13}$ P. Kung, X. Zhang, D. Walker, A. Saxler, J. Piotrowski, A. Rogalski, and M. Razeghi, Appl. Phys. Lett. 67, 3792 (1995). 